\title{
CARDIOLOGICAL OBSERVATIONS AT THE SIXTH BRITISH EMPIRE AND COMMONWEALTH GAMES
}

\author{
BY \\ F. W. BESWICK AND R. C. JORDAN \\ From the Physiology Department, University College of South Wales and Monmouthshire, Cardiff \\ Received September 30, 1960
}

The staging of the Sixth British Empire and Commonwealth Games at Cardiff in 1958 presented the opportunity for extension of an electrocardiographic study of the normal young man to include the changes that might result from intensive athletic training. A previous investigation (Jordan and Beswick, 1958) designed to establish the limits of normality for cardiac spatial electrical phenomena, as recorded by an orthogonal lead system based on the lead field theory of McFee and Johnston $(1953,1954 a$ and $b)$, had shown that, while about 85 per cent of normal subjects constituted a compact homogeneous population, the remainder demonstrated individual characteristics. It was, therefore, of interest to determine whether, or to what extent, a population of first-class athletes differed from the untrained both as a group and in the incidence of individual peculiarities.

Relatively little research has been attempted in the past at international athletic meetings, largely due to language difficulties, the paramount importance of avoiding interference with training schedules, and the natural suspicion of competitors and coaches that even the most innocuous procedures might adversely affect subsequent physical performance. At the Empire Games language difficulties were minimal and the other factors did not prevent 60 male competitors from readily volunteering for cardiological study.

The few electrocardiographic investigations that have previously been carried out on athletes have made use only of conventional clinical leads, chiefly for determination of the Einthoven triangular (RLF) plane vectors, and the results have not usually been analysed statistically. Since it is now known that the major electrical forces are oriented antero-posteriorly, RLF plane studies are inadequate to reveal more than a small fraction of spatial activity. The orthogonal approach used in the present survey, however, has allowed a more quantitative assessment of myocardial electrical phenomena and correlation with mechanical cardiovascular events.

\section{METHODS}

Each volunteer was encouraged to relax emotionally by watching the experimental procedure performed on another subject and then to relax physically lying supine on a couch with the headrest raised by $10^{\circ}$.

Using an Elema Elmqvist Mingograph type 23 direct-writing electrocardiograph, the standard limb leads I, II, and III and augmented voltage leads aVR, aVL, and aVF were first recorded at normal paper speed. Then scalar tracings were obtained at fast-speed (100 mm. a second) from the orthogonal leads of the lead field technique previously described (Jordan and Beswick, 1958), and the corresponding planar loops photographed from the screen of a Sanborn Vectorscope using a Cossor camera (Model 1428) on Kodak R60 35-mm. film. The lead selector switch of the instrument had been modified to permit the input of three independent bipolar leads. The electron beam was interrupted every $0.0025 \mathrm{sec}$. 
To eliminate variation due to sinus arrhythmia, the mean heart rates and time intervals for each subject were calculated from 15-20 cardiac cycles on the fast-speed records.

Vectorial analysis of the limb lead tracings was carried out in the traditional manner by plotting the mean algebraic sums of complex deflections from six cycles on the Einthoven reference frame. For the lead field data the planar vector angles were obtained by directly estimating the areas (microvolt-seconds) enclosed by the complexes and plotting them on rectangular co-ordinates. The corresponding spatial vector magnitudes $(M)$ were calculated from the formula, $M=\sqrt{a^{2}+b^{2}+c^{2}}$ where $a, b$, and $c$ are the projections on to leads $\mathrm{A}, \mathrm{B}$, and $\mathrm{C}$ respectively, and the spatial angle between QRS and T from

$$
\cos \angle(\mathrm{QRS}-\mathrm{T})=\frac{\left(a_{\mathrm{QRS}} \times a_{\mathrm{T}}\right)+\left(b_{\mathrm{QRS}} \times b_{\mathrm{T}}\right)+\left(c_{\mathrm{QRS}} \times c_{\mathrm{T}}\right)}{M_{\mathrm{QRS}} \times M_{\mathrm{T}}}
$$

For the presentation of vector angles and loops we have followed the notation of Helm (1956) for the three planes, as illustrated in Fig. 1.

FRONTAL

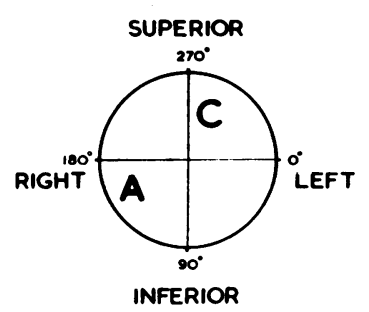

HORIZONTAL

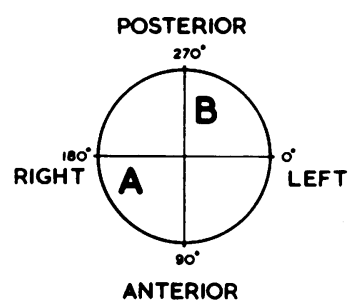

\section{SAGITTAL}

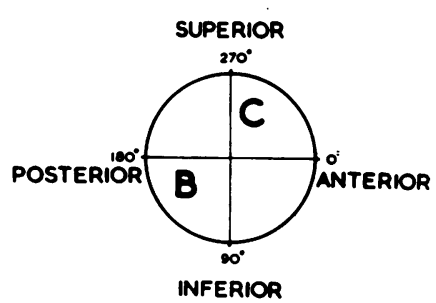

Fig. 1.-Orientation of planes and axes for description of loops and vector angles.

\section{RESULTS}

For analysis of heart rates, time intervals, and the qualitative assessment of vector loops, the results from all 60 athletes have been compared with the 47 normal students of a previous study (Jordan and Beswick, 1958). As in that study 8 of the 47 subjects had vectorial characteristics that separated them from the main homogeneous group, so 5 of the 60 athletes had quantitative features that lay outside the normal limits of variability to be expected from the means and distributions of important parameters. Consequently, for vectorial analysis, the 55 athletes of the homogeneous group have been compared with the corresponding population of 39 students and the unusual patterns of the other 5 examined separately.

The athletes were further sub-divided into a so-called "long-distance" group (1 mile and over) and a "short-distance" group (sprint, field events, ring events, etc.), the arbitrary division being made on the basis of endurance required for the competitive event, although it was realized that since, for example, the boxers' training involved long-distance road work the distinction was artificial.

\section{Heart Rates}

The mean resting supine heart rates and their distributions for the control group of 47 students and 60 athletes are shown in Fig. 2. The mean rate for all athletes was lower than for the controls by 8 beats a minute $(t=3 \cdot 6, \mathrm{P}<0 \cdot 01)$. When divided according to competitive event, the "shortdistance" men had a mean rate (65) that did not differ significantly $(t=1 \cdot 9, \mathrm{P}=0.05)$ from that of the untrained subjects, while the "long-distance" competitors with a mean value of 60 showed, as expected, the greatest difference from the controls $(t=3 \cdot 8, \mathrm{P}<0.01)$. 


\section{UNTRAINED STUDENTS}

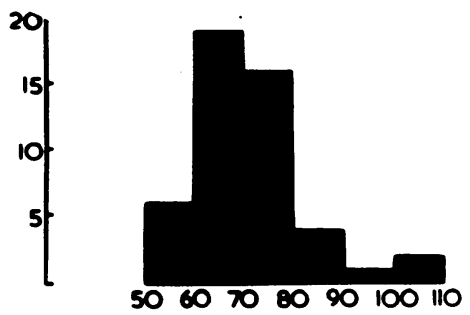

MEAN

70

S.D.II
60 ATHLETES

ALL EVENTS

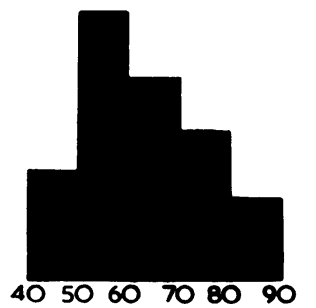

MEAN

62

S.D. 12
31 ATHLETES

LONG DISTANCE EVENTS
60

S.D. 12
29 ATHLETES SPRINT, FIELD, RING EVENTS
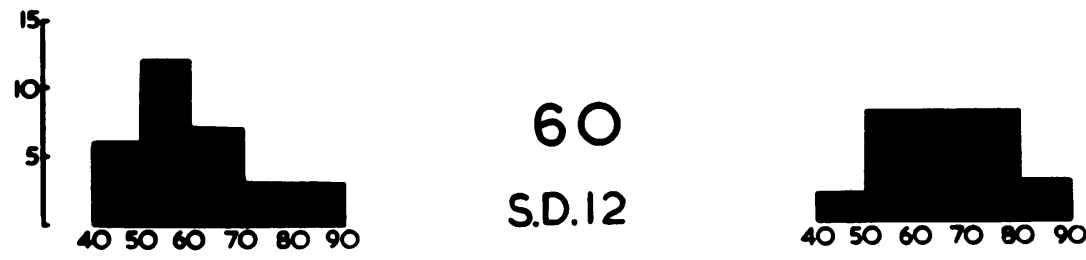

65

S.D. II

FIG. 2.-Distribution of resting heart rates for untrained students and athletes.

\section{$1 \cdot \mathrm{O} \mathrm{mV}$}
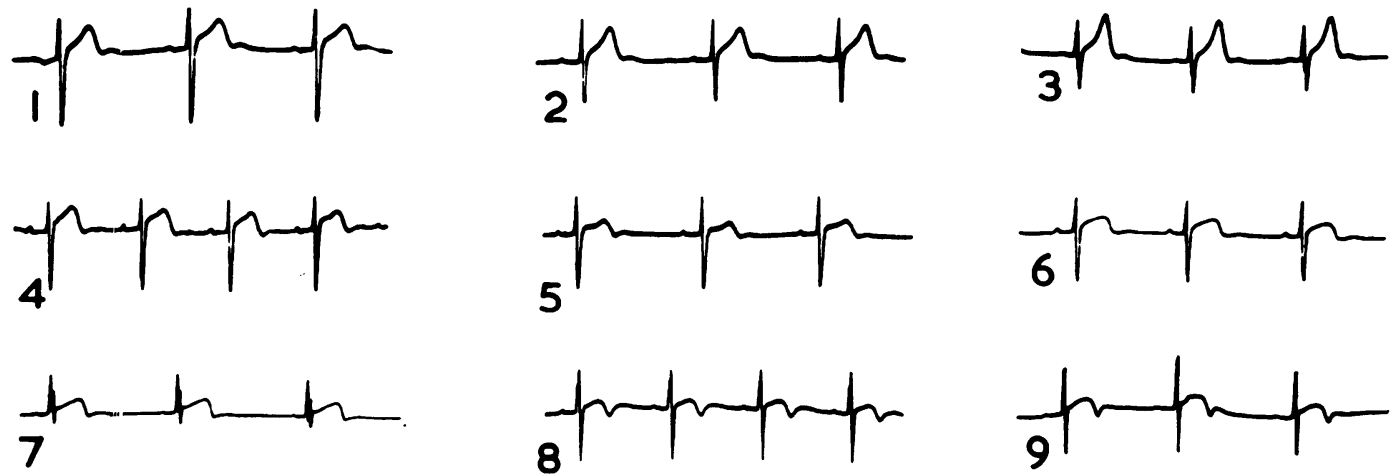

FIG. 3.-Typical examples of lead $B$ scalar tracings for the athletes, showing a gradation of $T$ complex pattern from the monophasic type $(1,2$, and 3$)$ usually encountered in the untrained to the diphasic type $(7,8$, and 9$)$ characteristic of approximately one-third of the athletes. 


\section{Qualitative Assessment of Athletes' Scalar Electrocardiograms}

Rhythm. Sinus arrhythmia was present in 38 of the 60 athletes and 2 showed occasional supraventricular extrasystoles.

$P$ Wave. The only peculiarities noted were that in lead $\mathrm{C}$ the voltages of 9 subjects tended to be unusually high and 2 had $P$ wave inversion in that lead.

QRS Complex. The limb leads showed right axis deviation in 16 competitors and left in 7 , of whom 3 had this feature to an extreme degree. The lead field frontal plane scalar tracings confirmed these findings. Notching was frequently observed, 42 subjects having it in at least one lead, most often in leads III, B, and C, in that order.

$T$ Wave. In approximately one-third of the athletes the $\mathrm{T}$ wave contour in lead $\mathrm{B}$ differed from that commonly seen in untrained adults. It was of a plateau-type with occasionally a distinct terminal component below the iso-electric line. Examples of these uncommon $\mathrm{T}$ forms are compared with the usual type in Fig. 3.

\section{Lead Field Planar Loops}

QRS Loop. Thirty-three competitors (Group A) gave loops that were similar in shape to those of the students (Jordan and Beswick, 1958) but often with increased initial anteriorly-directed electrical activity (see Fig. 4). The remainder were quite different but appeared to be of three

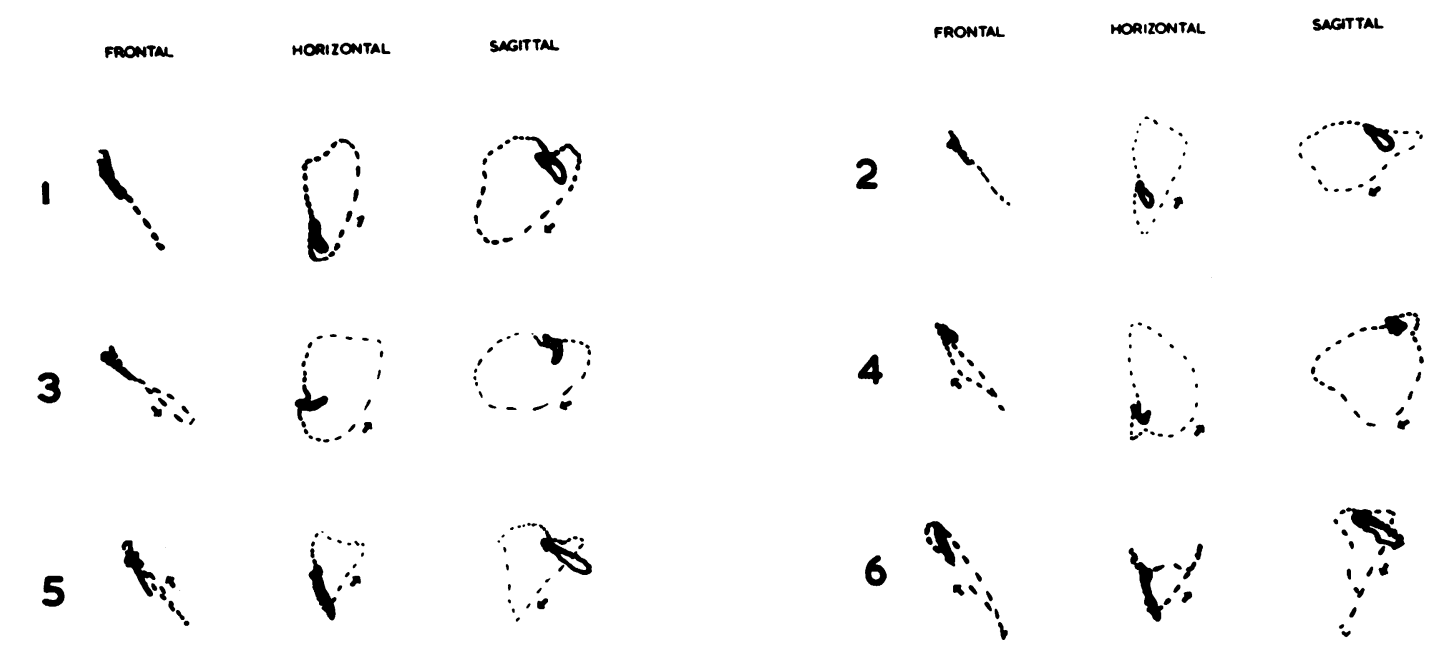

Fig. 4.-Typical planar vector loops for the athletes, showing the usual patterns (1 and 2$)$, the crescentic form of $T$ loop in the horizontal and sagittal planes ( 3 and 4$)$, and loss of postero-inferior electrical activity in the sagittal plane (5 and 6).

main types. In group B (11 subjects) there was loss of postero-inferior activity so that the sagittal plane loop had not its usual wide oval outline but was more pointed inferiorly, while the horizontal plane was concave posteriorly. Twelve subjects had QRS loops intermediate in form between those in Groups A and B. The remaining four yielded individually characteristic QRS loops that differed fundamentally from the other 56, as shown in Fig. $5(1-4)$.

$T$ Loop. In parallel with the observations quoted above on the scalar $\mathrm{T}$ wave contour, the $\mathrm{T}$ loops of about 35 per cent of the athletes differed from those commonly found in the untrained since they were crescentic with the proximal portion oriented normally while the distal portion was directed more posteriorly. Of the 33 subjects in Group A above, 11 showed this curvature to a greater or less degree while only 1 of the 11 in Group B showed it. It was also seen in 8 of the remaining 12 subjects in the "intermediate" group, in one of whom (see Fig. 5 (5)) the curvature was so extreme as to give the whole loop a predominantly posteriorly-directed axis. 

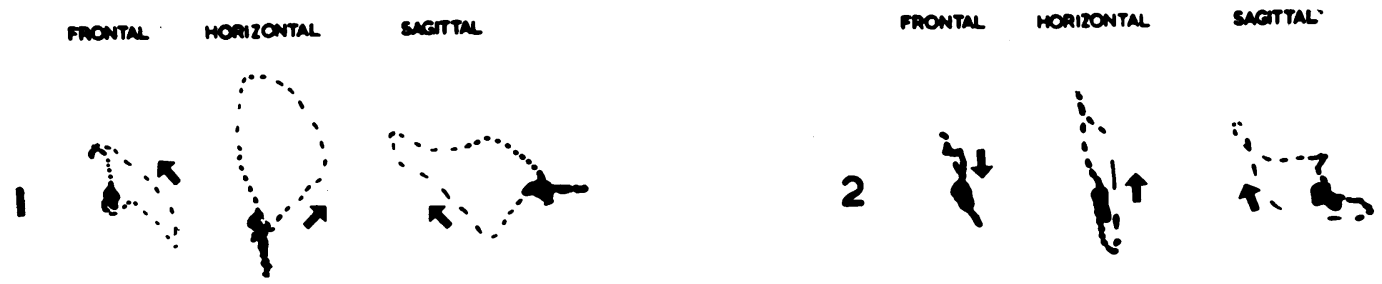

3
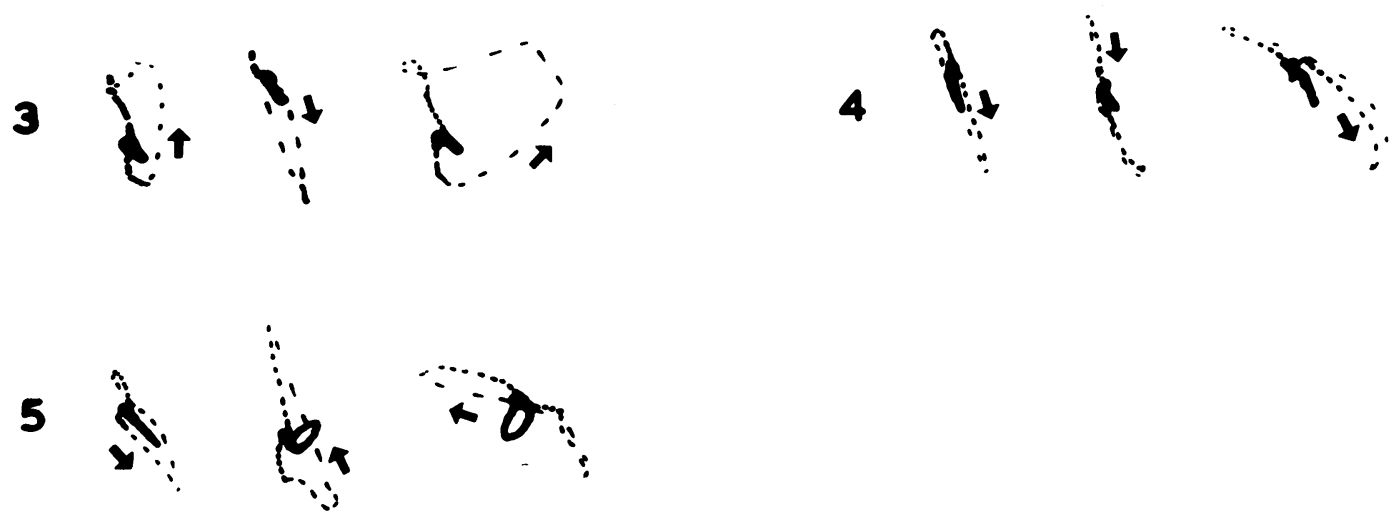

Fig. 5.-Planar loops of five athletes described separately in the text as possessing unusual features.

\section{Scalar Time Intervals}

$P-R$ Interval. The mean values for P-R interval in lead A for the athletes and students are given in Table I. No significant differences exist between the means of any of the groups but the scatter of observations was greatest among the long-distance runners. Six subjects, 3 students and 3

TABLE I

Mean Time Intervals, with their Standard Deviations, for Students and Athletes (Lead A)

\begin{tabular}{|c|c|c|c|c|c|}
\hline & & $\begin{array}{l}\text { Untrained } \\
\text { students }\end{array}$ & All athletes & $\begin{array}{c}\text { Short-distance } \\
\text { athletes }\end{array}$ & $\begin{array}{l}\text { Long-distance } \\
\text { athletes }\end{array}$ \\
\hline Number of subjects & & 47 & 60 & 29 & 31 \\
\hline $\mathbf{P}-\mathbf{R}$ interval & S.D. & $\begin{array}{l}0.15 \mathrm{sec} . \\
0.027\end{array}$ & $\begin{array}{l}0.15 \mathrm{sec} . \\
0.028\end{array}$ & $\begin{array}{l}0.15 \mathrm{sec} . \\
0.024\end{array}$ & $\begin{array}{l}0.15 \mathrm{sec} . \\
0.033\end{array}$ \\
\hline QRS duration & S.D. & $\begin{array}{l}0.08 \mathrm{sec} \\
0.011\end{array}$ & $\begin{array}{l}0.08 \mathrm{sec} . \\
0.012\end{array}$ & $\begin{array}{l}0.08 \mathrm{sec} . \\
0.010\end{array}$ & $\begin{array}{l}0.08 \mathrm{sec} . \\
0.013\end{array}$ \\
\hline T complex time & S.D. & $\begin{array}{l}0.29 \mathrm{sec} \\
0.031\end{array}$ & $\begin{array}{l}0.32 \mathrm{sec} . \\
0.042\end{array}$ & $\begin{array}{l}0.31 \mathrm{sec} . \\
0.039\end{array}$ & $\begin{array}{l}0.34 \mathrm{sec} . \\
0.039\end{array}$ \\
\hline
\end{tabular}

marathon competitors, had P-R intervals exceeding the commonly accepted normal upper limit of $0.20 \mathrm{sec}$. and one marathon runner had the abnormally low value of $0.08 \mathrm{sec}$. No correlation was demonstrated between the $P-R$ interval and duration of the cardiac cycle ( $R-R$ time) in the students or athletes, the respective values for $r$ being -0.03 and -0.05 with probabilities of 0.8 and $0 \cdot 7$.

QRS Duration. The mean values for QRS duration given in Table I indicate no differences 
between the various groups. The correlation coefficients for $Q R S$ duration and $R-R$ time show significant negative correlation $(r=-0.46, \mathrm{P}<0.01)$ in the case of the long-distance athletes, but not in the other two groups (students: $r=-0.02, \mathrm{P}=0.9$; short-distance athletes: $r=-0.08$, $\mathrm{P}=0 \cdot 6-0 \cdot 7)$.

$T$ Complex Time. The durations of the $\mathrm{T}$ complex $[(\mathrm{S}-\mathrm{T})+\mathrm{T}]$ for students and athletes are also presented in Table $I$. There was a mean increase of $0.03 \mathrm{sec}$. in the athletes as compared with the untrained $(t=4 \cdot 1, \mathrm{P}<0.01)$. When the athletes were subdivided a difference of $+0.03 \mathrm{sec}$. appeared between the long- and short-distance groups $(t=2 \cdot 9, \mathrm{P}<0.01)$ but the difference between the short-distance competitors and students was of doubtful significance $(t=2 \cdot 4, \mathrm{P}=0 \cdot 01-0.02)$. A positive correlation was noted between $T$ complex time and cardiac cycle length for all subjects, the correlation coefficients being $+0.65(t=5.8, \mathrm{P}<0.01)$ and $+0.82(t=10.9, \mathrm{P}<0.01)$ respectively. The corresponding regression equations

T complex time $=0 \cdot 160(\mathrm{R}-\mathrm{R})+0 \cdot 151$. For students.

$T$ complex time $=0 \cdot 168(R-R)+0 \cdot 152$. For all athletes.

do not differ significantly $(t=0 \cdot 25, \mathrm{P}=0 \cdot 8)$, i.e. the $\mathrm{T}$ complex time bears the same relation to $\mathrm{R}-\mathrm{R}$ in both groups.

\section{Vectorial Analysis}

The RLF plane vector angles calculated from leads I and II are given in Table II. No significant differences were found between the values for QRS, T, or QRS-T angles for students and athletes [QRS: $t=0 \cdot 82, \mathrm{P}=0 \cdot 4 ; \mathrm{T}: t=1 \cdot 21, \mathrm{P}=0 \cdot 2 ; \mathrm{QRS}-\mathrm{T}: t=0 \cdot 17, \mathrm{P}=0 \cdot 8-0 \cdot 9]$.

TABLE II

Mean RlF Plane Vector Angles from Leads I and II and Lead Field Frontal Plane Angles WITH THEIR STANDARD DEVIATIONS

\begin{tabular}{l|c|c|c|c|c|c}
\hline & \multicolumn{3}{|c|}{ Students } & \multicolumn{3}{c}{ Athletes } \\
\cline { 2 - 8 } & QRS & T & QRS-T & QRS & T & QRS-T \\
\hline RLF plane .. .. .. & $68^{\circ}(21)$ & $40^{\circ}(22)$ & $+29^{\circ}(28)$ & $64^{\circ}(24)$ & $35^{\circ}(17)$ & $+29^{\circ}(27)$ \\
\hline $\begin{array}{l}\text { RLF plane values converted } \\
\text { to frontal plane by isosceles } \\
\text { triangular reference frame }\end{array}$ & $60^{\circ}(18)$ & $55^{\circ}(14)$ & $+5^{\circ}(21)$ & $56^{\circ}(18)$ & $52^{\circ}(11)$ & $+4^{\circ}(19)$ \\
\hline Lead field frontal plane $\ldots$ & $60^{\circ}(16)$ & $55^{\circ}(14)$ & $+5^{\circ}(19)$ & $57^{\circ}(18)$ & $49^{\circ}(13)$ & $+8^{\circ}(22)$ \\
\hline
\end{tabular}

It has been shown previously (Jordan and Beswick, $1960 \mathrm{~b}$ ) that for the students the RLF plane vector angles can be converted closely to the corresponding lead field frontal plane angles by using a special right-angled isosceles triangular reference frame. The values presented in Table II demonstrate that this conversion can also be applied to the athletes.

The lead field mean vector angles for both frontal and horizontal planes can be compared in Table III. There is no real difference between the QRS angles in the frontal plane for the untrained and all the athletes treated together, but the long-distance competitors have a more transverse axis than the short-distance by about $10^{\circ}(t=2 \cdot 4, \mathrm{P}=0.01-0.02)$. Similarly the mean frontal plane $T$ angle for all athletes was more transverse than for the students $(t=2 \cdot 09, \mathrm{P}=0.02-0.05)$, the difference being greatest with the long-distance runners. The ventricular gradient (VG) in this plane followed the same pattern and was most horizontal in those athletes indulging in the most sustained effort. The relative positions of QRS and T in the frontal plane (QRS-T angle) were not affected by athletic training.

The greatest vectorial angular differences occurred in the horizontal plane where the athletes' 
TABLE III

Lead Field Planar and Spatial Mean Vector Angles with their Standard Deviations

\begin{tabular}{|c|c|c|c|c|c|c|c|c|}
\hline & & & & & Students & All athletes & $\begin{array}{l}\text { Short-distance } \\
\text { athletes }\end{array}$ & $\begin{array}{l}\text { Long-distance } \\
\text { athletes }\end{array}$ \\
\hline \multicolumn{2}{|c|}{ Number of subjects } & .. & .. & .. & 39 & 55 & 26 & 29 \\
\hline $\begin{array}{l}\text { Frontal } \\
\text { plane }\end{array}$ & $\left\{\begin{array}{l}\text { QRS } \\
\mathrm{T} \ldots \\
\text { VG } \\
\text { QRS-T }\end{array}\right.$ & $\begin{array}{l}\ldots \\
\cdots \\
\cdots \\
.\end{array}$ & $\begin{array}{l}. . \\
\cdots \\
\cdots \\
.\end{array}$ & $\begin{array}{l}\ldots \\
\cdots \\
\cdots \\
\cdots\end{array}$ & $\begin{array}{r}60^{\circ}(16) \\
55^{\circ}(14) \\
58^{\circ}(11) \\
+5^{\circ}(19)\end{array}$ & $\begin{array}{r}57^{\circ}(18) \\
49^{\circ}(13) \\
54^{\circ}(10) \\
+8^{\circ}(22)\end{array}$ & $\begin{array}{r}63^{\circ}(13) \\
50^{\circ}(14) \\
57^{\circ}(10) \\
+13^{\circ}(20)\end{array}$ & $\begin{array}{r}52^{\circ}(20) \\
48^{\circ}(12) \\
51^{\circ}(10) \\
+4^{\circ}(22)\end{array}$ \\
\hline $\begin{array}{l}\text { Horizontal } \\
\text { plane }\end{array}$ & $\left\{\begin{array}{l}\text { QRS } \\
\mathrm{T} . . \\
\text { VG } \\
\text { QRS-T }\end{array}\right.$ & $\begin{array}{l}. \\
\cdots \\
\cdots \\
\cdots\end{array}$ & $\begin{array}{l}. \\
\cdots \\
\cdots \\
\cdots\end{array}$ & $\begin{array}{l}. . \\
\cdots \\
\cdots \\
.\end{array}$ & $\begin{array}{r}299^{\circ}(19) \\
70^{\circ}(10) \\
50^{\circ}(16) \\
+131^{\circ}(23)\end{array}$ & $\begin{array}{r}338^{\circ}(44) \\
66^{\circ}(14) \\
53^{\circ}(20) \\
+87^{\circ}(43)\end{array}$ & $\begin{array}{r}342^{\circ}(47) \\
68^{\circ}(12) \\
54^{\circ}(20) \\
+86^{\circ}(45)\end{array}$ & $\begin{array}{r}334^{\circ}(40) \\
63^{\circ}(16) \\
52^{\circ}(19) \\
+88^{\circ}(41)\end{array}$ \\
\hline Spatial & QRS-T & .. & .. & .. & $+100^{\circ}(17)$ & $+74^{\circ}(32)$ & $+73^{\circ}(28)$ & $+75^{\circ}(34)$ \\
\hline
\end{tabular}

mean QRS vectors were directed more anteriorly than those of the untrained by about $40^{\circ}(t=5 \cdot 17$, $P<0.01)$ and all athletes were affected to the same extent. Since the $T$ vector angles in this plane did not differ with training, the large decrease of $44^{\circ}$ in QRS-T angle for the athletes $(t=5 \cdot 77$, $P<0.01$ ) was a consequence of the more anterior location of $Q R S$ in conjunction with the narrower spatial QRS-T angle in the trained subjects (see Fig. 6). Despite the change in spatial direction of QRS, the orientation of the ventricular gradient remained constant and in each plane the values for students and athletes did not differ significantly.

\section{9 \\ UNTRAINED STUDENTS}

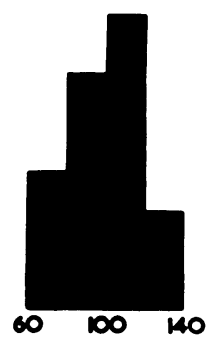

MEAN $100^{\circ}$

S D 17
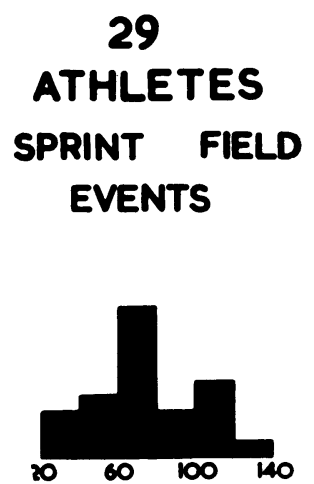

31

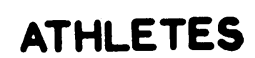

LONG DISTANCE

EVENTS

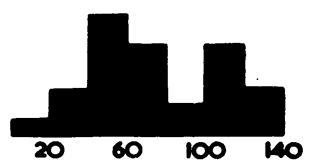

In Table IV are given the corresponding spatial vector magnitudes. The value for QRS calculated in the usual manner by algebraic summation of scalar areas was unaffected by athletic training but the "total QRS" magnitude derived from arithmetic summation, irrespective of 
TABLE IV

Mean Lead Field Spatial Vector Magnitudes (in Microvolt-Seconds) with their Standard DEVIATIONS

\begin{tabular}{|c|c|c|c|c|c|}
\hline & & Students & All athletes & $\begin{array}{l}\text { Short-distance } \\
\text { athletes }\end{array}$ & $\begin{array}{l}\text { Long-distance } \\
\text { athletes }\end{array}$ \\
\hline QRS & .. & $34(14)$ & $30(9)$ & $28(9)$ & $31(8)$ \\
\hline "Total QRS" & .. & $53(15)$ & $43(10)$ & $38(8)$ & $48(9)$ \\
\hline $\begin{array}{lll}\mathbf{T} & \ldots & \end{array}$ & . & $80(24)$ & $90(32)$ & $71(22)$ & $106(31)$ \\
\hline $\begin{array}{lll}\text { VG } \ldots & \ldots \\
\end{array}$ & $\cdots$ & $82(25)$ & $101(33)$ & $83(23)$ & $118(31)$ \\
\hline T/“"Total QRS" & $\ldots$ & $1.6(0.6)$ & $2 \cdot 1(0 \cdot 8)$ & $1.9(0.6)$ & $2 \cdot 4(0.95)$ \\
\hline
\end{tabular}

relation to the isoelectric line (see Jordan and Beswick, 1958), showed considerable variation. This magnitude for the short-distance group was lower than for the students $(t=4.63, \mathrm{P}<0.01)$ and for the long-distance competitors $(t=4 \cdot 16, \mathrm{P}<0 \cdot 01)$. The spatial $\mathrm{T}$ vector magnitude for the longdistance men was greater than for the short-distance $(t=4.69, \mathrm{P}<0.01)$ and untrained subjects $(t=3 \cdot 86, \mathrm{P}<0 \cdot 01)$. Similar relations obtained for the ventricular gradient magnitudes.

The ratio of spatial T magnitude to "total QRS" was the same for students and short-distance athletes but was increased by nearly 50 per cent for the long-distance runners due to the increase in magnitude of $T$.

\section{Discussion}

Heart Rates. Little conclusive information is available concerning the effect of athletic training on resting heart rate. The assertion of Cureton (1951) that "a well trained athlete has a lean, strong heart which gives a full stroke range and slow beat" is opposed to the view of Brouha and Heath (1943) who denied that there was any correlation between basal pulse rate and physical fitness for strenuous exercise. The opinion of Cotton (1932) that "no data have been published giving the exact status of a series of athletes and their respective pulse rates" remains broadly true today.

Studies on the recumbent pulse rates of large numbers of normal untrained subjects are scanty. The major more recent studies on non-athletes have been carried out on military personnel. Schneider and Truesdell (1922), reporting on 2000 male Air Force recruits, gave a mean reclining pulse rate of 74 (S.D. 10) and Graybiel et al. (1944) investigated 1000 similar subjects and obtained a mean of 64 a minute. In 1943, Brouha and Heath determined the recumbent rates for 252 unselected college students and folnd a mean of 66 (range 40-100). The overall mean for the 3252 young men of these three surveys was identical with the mean for the control group of the present study (70, S.D. 11).

Some of the earliest investigations on the pulse rates of world-class athletes were those of Bramwell and Ellis (1930) and Hoogerwerf (1930) at the Amsterdam Olympic Games in 1928. The latter's mean result for 260 sitting subjects, who included many short-distance runners, ring competitors, etc., was 50 beats a minute; while Bramwell and Ellis's value for 108 runners, cyclists, and weightlifters was 65: if this last series is divided to correspond to our long- and short-distance groups, the mean rates become: long, 60 and short, 69 . These results are not directly comparable with ours because of the difference in posture but if allowance is made by reducing Bramwell and Ellis's value by 7 , which was the mean decrease on changing from the sitting to the recumbent posture observed by Brouha and Heath (1943), they are then in reasonable agreement with the Empire Games data.

The mean resting heart rates given in Fig. 2 show that athletic training had resulted in a mean 
decrease of 8 beats a minute which agrees with the findings of Cotton (1932). On the other hand, Knehr et al. (1942), comparing the pulse rates of 14 students before and after six months' training for middle-distance running, observed a mean fall of only 5 beats, which was of similar magnitude to the observations of Karvonen et al. (1957).

The lowest pulse rate for any single category of athlete in the present study was 58 (range 40-81) for the 15 marathon runners examined, a value that corresponds closely with the figure of 57 (range 40-72) observed by Beckner and Winsor (1954) for 165 marathon men in California.

Among our athletes those with the lowest heart rates were invariably long-distance runners but none had a rate lower than 40 although normal sinus rates below that have occasionally been observed among the general population (White, 1942). From the available evidence it would appear that the most rigorous training for long-distance events is likely to reduce the resting rate to between 50 and 60 beats a minute but only rarely to 40 or below.

While the majority of athletes have relatively slow resting pulse rates there are many exceptions. Among the Empire Games competitors the highest rate observed was 88 but several authors have quoted cases of resting sinus tachycardia in highly trained subjects. Of the 650 Finnish athletes examined by Klemola (1951), 7 had rates of over 100, and Segers et al. (1956) found that 4 out of 205 athletes had similar degrees of tachycardia. Wolffe (1957) also cited the cases of two marathon runners who had resting rates of 120 and 130 respectively. In some cases, probably in most, these high rates are due to emotional disturbance due to pre-race tension and to the procedure of medical, and especially cardiographic, examination (Brouha and Heath, 1943) and although at the Empire Games everything was done to allay apprehension and thus to secure basal rates, nevertheless three of the athletes examined showed signs of anxiety at the sight of electronic equipment and their pulse rates were probably unduly high.

It would appear, therefore, that the pulse rate per se should not be used as an index of fitness for extreme exertion since the range of normality is so wide. The competitor's own previous athletic performance is a surer test of physical fitness and a tachycardia should only be regarded as inimical to participation in athletics when it is associated with organic disease.

\section{Scalar Time Intervals}

With the apparatus available it was not possible to record all three orthogonal leads synchronously, which is the only method by which absolute time intervals can be determined. Nevertheless, since all the previously published data concerning these intervals in athletes have been derived from single limb lead slow-speed tracings, it was considered justifiable to present similar, but more accurate, values from our fast-speed records. The durations of $P$, however, were regarded as so equivocal as not to warrant separate consideration. Although the time intervals for all three orthogonal leads were analysed, only those from lead A are discussed here as being typical and comparable with the classical lead I.

We have considered it more rational to relate the time intervals to total cycle length $(R-R)$, of which they are obviously constituent parts, rather than to heart rate to which they are less directly related. It should be emphasized that, contrary to the implication of many reported statements, a quantity cannot be related linearly to both rate and cycle length.

$P-R$ Interval. The mean durations of $\mathrm{P}-\mathrm{R}$ were the same for the untrained and both groups of athletes, but the scatter of observations was greatest among the long-distance runners. In previous studies several authors have drawn attention to the frequency with which values greater than $0 \cdot 20$ sec. are encountered in athletes. For example, Reindell (1943) found that approximately 9 per cent of competitors had values of $0.21 \mathrm{sec}$. or more. The Empire Games results would suggest that these high values are no more prevalent in marathon runners than in the untrained and that the higher limit for normality of $0.22 \mathrm{sec}$. given by Evans (1954) is more appropriate in clinical practice. Savilahti (1946) also suggested the same higher limit but he arbitrarily assumed that the best estimate of P-R was given by its greatest value in any lead whereas the true P-R time may be shorter than that given by any single lead (Pipberger and Tanenbaum, 1958). 
It has been stated that the P-R interval becomes shorter as the heart quickens (e.g. Goldberger, 1953) but a contrary conclusion was that of Savilhati (1946) who believed that "the generally accepted idea of the dependence of $P-Q(R)$ time on the pulse frequency is not correct." When an attempt was made in the present study to correlate $P-R$ interval with cardiac cycle length, no statistical correlation could be demonstrated for either students or athletes.

The unusually short P-R time $(0.08 \mathrm{sec}$.) of one of the marathon competitors did not appear to be associated with a Wolff-Parkinson-White syndrome, since the QRS time was not prolonged in any lead, nor was there any abnormal inversion of $T$.

$Q R S$ Duration. Trethewie (1958) claimed that in approximately half the Australian athletes whom he investigated in 1953 there was "widening of the QRS complex," but no actual data were presented. A similar assertion was made by Beckner and Winsor (1954) but our results give no indication of any increase of QRS duration in the athletes. There is also difference of opinion concerning the relation between QRS duration and heart rate. Bazett (1920) and Savilhati (1946) stated that QRS time diminished as heart rate increased but Lepeschkin (1951) maintained that there may be no apparent relation due to the interaction of conflicting influences. The data for the students and short-distance athletes in the present investigation showed no correlation between QRS time and length of the cardiac cycle $(r=0.02, \mathrm{P}=0.9)$ but in the case of the long-distance competitors there was a negative correlation $(r=0.46, \mathrm{P}<0.01)$.

$T$ Complex Duration. Although it is customary to measure separately the S-T interval and the duration of $\mathrm{T}$, there are good reasons for combining them into a single physiological unit. It has been shown (Macleod, 1938; Chernoff and Nahum, 1949) that repolarization is already in progress at the end of QRS and, therefore, it is more accurate to regard S-T plus T as the duration of repolarization and term it the T complex time (Lepeschkin, 1951).

Few data are available relating the duration of the $T$ complex to physical training but the present results demonstrate that it is increased by a mean value of $0.03 \mathrm{sec}$. in the athletes as a whole compared with the untrained students, the difference tending to be greater for the long-distance competitors.

The fact that repolarization time is related to $R-R$ duration in both trained and untrained subjects over the range of our observations was strongly suggested by scatter diagrams and, although the relationship cannot be linear over the whole range of $\mathbf{R}-\mathbf{R}$ times, it was considered justifiable to calculate a linear regression for these observations within the physiological range. The equation for the students, $T$ complex time $=0 \cdot 160(R-R)+0 \cdot 151$, probably over-estimates the time of repolarization in pronounced tachycardias. It would appear that whatever factors slow the heart rate, by inhibiting depolarization in the S-A node, also prolong repolarization in the ventricular myocardium but, as will be shown later, these structures are not affected to the same extent.

Although the distribution of $\mathrm{R}-\mathrm{R}$ times for all athletes was around a larger mean, the corresponding $T$ complex durations gave a regression line $-T$ complex time $=0 \cdot 168(R-R)+0 \cdot 152-$ that did not differ significantly from that of the students. In other words, athletic training did not modify the usual relation between S-A nodal sensitivity and ventricular repolarization.

$Q-T$ Interval. Since the Q-T interval represents the time required for depolarization plus repolarization of the ventricular musculature, it approximates to the period of mechanical contraction and is influenced by factors affecting heart rate and the state of the myocardium. White and Mudd (1929) originally stated that "the measurement of the duration of Q-T is apparently of little or no clinical value" but it has become apparent that conditions causing ventricular overloading and certain abnormal metabolic processes are frequently associated with prolongation of the Q-T interval (Sodi-Pallares and Calder, 1956). Some physiological factors may also affect the Q-T interval, as was shown by Robb and Turman (1947).

The variation of Q-T duration with heart rate has been expressed mathematically by several authors using different types of formulæ. The relation between Q-T and R-R, like that between $T$ complex time and R-R, must theoretically be curvilinear and some investigators (e.g. Bazett, 1920; and Fridericia, 1920) have devised equations that attempt to allow for this feature. However, 
over the physiological range a simple linear expression satisfactorily characterizes these variables as shown by Schlamowitz (1946). When such a linear treatment was made for the present data there were no significant differences between the regression lines for students, short-distance, or long-distance athletes, and it was justifiable to calculate a best straight line to fit all the values irrespective of athletic training. The derived expression, $\mathrm{Q}-\mathrm{T}=0 \cdot 184(\mathrm{R}-\mathrm{R})+0 \cdot 217$, is generally similar to earlier equations (see Lepeschkin, 1951).

In an attempt to establish a value for Q-T that was independent of heart rate, the New York Heart Association (1953) recommended that Bazett's $K[Q-T / \sqrt{ } R-R]$ should be used on the assumption that K was constant for all subjects. Robb (1950), however, has proved that $\mathrm{K}$ is not normally distributed around the mean value of 0.37 (Bazett, 1920) or of 0.39 (Ashman and Hull, 1941) and that it varies with cardiac cycle length. She also observed that athletes tended to have larger $\mathrm{K}$ values than the untrained and the mean figures calculated from the Empire Games data (Table V) also suggest that this is the case.

TABLE V

Some Functions of Mean Q-T Time, with their Standard Deviations, for Students and Athletes

\begin{tabular}{|c|c|c|c|c|c|}
\hline & & & Q-T duration & $\frac{\mathrm{Q}-\mathrm{T}}{\sqrt{\overline{\mathrm{R}-\mathrm{R}}}}$ & $\frac{\mathrm{Q}-\mathrm{T}}{\mathrm{R}-\mathrm{R}}$ \\
\hline $\begin{array}{ll}. & .\end{array}$ & .. & .. & $\begin{array}{l}0.37 \mathrm{sec} . \\
(0.029)\end{array}$ & $\begin{array}{l}0.39 \mathrm{sec} . \\
(0.024)\end{array}$ & $\begin{array}{c}0.43 \mathrm{sec} . \\
(0.048)\end{array}$ \\
\hline Short-distance athletes & .. & .. & $\begin{array}{l}0.39 \mathrm{sec} . \\
(0.041)\end{array}$ & $\begin{array}{l}0.40 \mathrm{sec} . \\
(0.024)\end{array}$ & $\begin{array}{l}0.41 \mathrm{sec} . \\
(0.041)\end{array}$ \\
\hline Long-distance athletes & .. & . $\quad .$. & $\begin{array}{l}0.42 \mathrm{sec} . \\
(0.045)\end{array}$ & $\begin{array}{l}0.41 \mathrm{sec} . \\
(0.025)\end{array}$ & $\begin{array}{l}0.405 \mathrm{sec} \\
(0.055)\end{array}$ \\
\hline
\end{tabular}

From a physiological standpoint it would appear that the simple ratio $\mathbf{Q}-\mathbf{T} / \mathbf{R}-\mathbf{R}$ is of more fundamental importance since it approximately relates duration of mechanical contraction to cycle length. The mean value of 0.43 (Table $\mathrm{V}$ ) for our students is slightly lower than that of Pipberger and Tanenbaum (1958) who found this ratio to be 0.46 in synchronously recorded orthogonal leads. Of greater interest is the fact that, although the absolute value of $Q-T$ increases from students to long-distance runners, $Q-T / R-R$ tends to decrease in the same order. This would imply that at the given heart rate the duration of ventricular mechanical contraction is relatively shorter in the athlete and diastolic filling time correspondingly lengthened. This finding may be related to the large diastolic size characteristic of the resting athlete's heart (Winsor and Beckner, 1955; Jokl et al., 1958) and its increased stroke volume (Steinhaus, 1933; Stewart and Watson, 1940; Rushmer, 1959), the latter being favoured by the absolute increase in Q-T. Also, since the major coronary blood flow occurs during diastole (Gregg and Green, 1940), it is reasonable to suggest that these adaptations to strenuous exercise would increase the availability of nutrients to the myocardium.

In the experimental animal, Robb and Turman (1947) observed a decrease in the $Q-T / R-R$ ratio following vagal stimulation and the finding of a similar reduction in the resting athlete is probably another manifestation of increased vagal tone.

\section{Planar Loops}

The frontal plane QRS loops of the athletes showed no characteristic differences from those of the students (Jordan and Beswick, 1958) but inspection of the horizontal and sagittal loops revealed much wider variability in shape. The athletes of Group A (see Results) whose QRS loops most closely resembled those of the students, tended to exhibit increased initial anteriorly-directed activity, and this appeared to be progressively accentuated through an intermediate group to Group 
B where the loops were distinguished by relatively excessive anterior activity with loss of posterior forces, only the vertical voltages remaining approximately constant.

These features are consistent with some degree of right ventricular hypertrophy in the athletes since they are characteristic of the QRS loops of infants (Jordan and Beswick, unpublished observations) as a result of their physiological right-sided preponderance. In the child vectorcardiogram also the posterior curvature of the distal portion of the $T$ loop makes it appear crescentic in the horizontal and sagittal planes. Similar curvature was observed in about one-third of the athletes and may further support the suggestion of right ventricular hypertrophy as a result of intensive athletic training.

In this connection it may be noted that Grusin (1954) and Powell (1959) have reported a high incidence of præcordial lead T complex patterns in the African native similar to the diphasic $T$ waves illustrated in Fig. 3 corresponding to the crescentic T loops of some of the athletes. Previously, Littman (1946) had attributed this type of $T$ wave to "a persistence of the juvenile pattern and not to a manifestation of organic heart disease." In the Empire Games athletes these $T$ wave changes occurred chiefly among the white competitors, but it may be that increased vagal tone together with reversion to the cardiopulmonary conditions peculiar to early life are responsible for this phenomenon.

\section{Vectorial Analysis}

There is no unanimity among previous authors regarding the effects of athletic training on the QRS electrical axis in the RLF plane. Glasser (1947) found the mean value for a large group of athletes to be $50^{\circ}$ indicating some degree of left axis deviation, but Beckner and Winsor (1954) obtained a mean value $13^{\circ}$ more vertical than for their control group. Terranova and Fernandez (1958) claimed to have demonstrated a prevalence of right axis deviation which they suggested was due to "functional hyper-activity of the right ventricle." The results of the present study indicate no differences between the QRS or T vector angles in this plane (Table II) for students and athletes.

In the lead field frontal plane the only differences were between the untrained and the long-distance runners (Table III), the latter having more transverse QRS and T vectors although the mean QRS-T angle remained unaltered. These changes are consistent with a more transverse anatomical position of the heart in the long-distance men rather than a left ventricular preponderance and may be due to the higher resting position of the diaphragm in athletes, in whom it has been claimed that this muscle plays a more prominent part in alveolar ventilation (Hornicke, 1924; Karpovich, 1955). This suggestion is also supported by the finding of Kohlrausch (1921) that the arm action in longdistance competitors immobilizes the chest and encourages a diaphragmatic type of respiration.

The most striking vectorial difference was the narrowing of the spatial QRS-T angle in the athletes (see Fig. 6): this is reflected in the horizontal planar values given in Table III where it is seen to be due primarily to anterior displacement of QRS with T remaining constant. The histograms of spatial QRS-T angles for the athletes suggest the possibility of dual populations in each group, one closely resembling the untrained with a mean spatial angle of $100^{\circ}$, and the other having a mean angle of about $50-60^{\circ}$. This dichotomy could well be regarded as a consequence of two types of cardiac adaptation to strenuous exercise only one of which resulted in change of electrical activity. In those subjects in whom narrowing of the angle occurred, the effect was such as might be expected in minor degrees of right ventricular hypertrophy since Elek et al. (1954), Richman and Wolff (1955), and Milnor (1957) have all demonstrated anterior displacement of spatial QRS in this condition. As a result of catheterization studies, Freedman et al. (1955) have also suggested that during the course of rigorous training the right ventricle is exposed to inflow overloading so that pressure conditions simulate those of atrial septal defect.

In infants and children similarly narrow spatial QRS-T angles are usually encountered and the overall electrocardiographic findings are of "uncomplicated right ventricular hypertrophy as compared with the relative size of the two ventricles in older individuals" (Ziegler, 1951) although analysis of the RLF plane data alone might erroneously indicate a left axis deviation that could be 
ascribed to a more horizontal anatomical axis of the heart. The analogy between the hearts of athletes and infants is also supported by the common similarity of the $\mathrm{T}$ loop contour, as discussed earlier.

The mean spatial vector magnitudes for QRS of all groups (see Table IV) do not differ significantly, but this does not imply that the electrical activity associated with depolarization is the same for all. These vector magnitude values, as derived from algebraic summation of scalar tracing areas, depend not only on the size and rate of change of body surface potentials but also on the distribution of those potentials about the iso-electric point in space. Consequently, it is possible for large voltage-time records to yield small QRS spatial vector magnitudes if the orthogonal scalar complexes are diphasic with approximately equal areas above and below the iso-electric line in each lead. The "total QRS" spatial magnitude, on the other hand, attempts to estimate the overall quantity of body surface electrical activity since it is obtained by arithmetic summation of the areas both above and below the iso-electric line in all three orthogonal leads. Whereas the spatial magnitude of mean QRS as traditionally derived is a true vector quantity related to the area of the $\mathrm{R}$ deflection minus the area of the $\mathrm{S}$ deflection in all three leads, the "total QRS" spatial magnitude is a true scalar quantity and is related to the area of $\mathrm{R}$ plus the area of $\mathrm{S}$ in all three leads.

In contrast with the mean spatial QRS vector magnitudes, the mean "total QRS" magnitudes showed marked differences between the untrained and trained subjects. Although it might have been anticipated that with some degree of right ventricular hypertrophy in the athletes there would have resulted an increase in "total QRS" magnitude, the reverse was the case since the mean values for all athletes were significantly lower than for the students $(t=3 \cdot 85, \mathrm{P}<0 \cdot 01)$. In attempting to account for this apparent anomaly, the fundamental factors governing body surface potentials of cardiac origin must be considered.

The electrical activity associated with ventricular myocardial depolarization, which can be recorded by direct leads from the heart surface, is that remaining after partial neutralization as a result of intracavitary and intramyocardial short-circuiting; and of this resultant activity only a small fraction can be detected at the body surface, because of further short-circuiting within the tissues surrounding the heart. In addition, the forces responsible for the body surface potentials must themselves be regarded as resultants of numerous instantaneous dipoles systematically distributed throughout the ventricles during depolarization. Usually the activity of the left ventricle exceeds that of the right to give a net mean spatial QRS vector directed downward to the left and posteriorly.

In the athlete it is possible that some relative right ventricular hypertrophy would have the effect of reducing the net cardiac field and giving smaller manifest surface activity as well as displacing the mean spatial QRS anteriorly. In addition, the probable greater diastolic and coronary filling in the resting athlete, as discussed earlier, may also contribute to the smaller mean "total QRS" magnitude in this group.

Since the electrical events of repolarization occur during mechanical systole, the factors modifying the distribution of potentials at the body surface are fundamentally different from those present during depolarization. For example, the short-circuiting effects of intracavity and intracoronary blood will be reduced and the internal resistance of the myocardial fibres decreased (Lepeschkin, 1951), resulting in a larger fraction of the total cardiac electrical activity appearing at the body surface during repolarization than during depolarization.

A further basic difference between the electrical events of these two phases is in respect to the spatial distribution of instantaneous vectors in relation to the iso-electric point. Whereas the instantaneous vectors that determine the outline of the QRS loop are directed successively into more than one spatial octant, the corresponding forces for $T$ are usually directed exclusively into one octant. This dissimilarity is reflected in the essentially diphasic nature of QRS and monophasic nature of $\mathrm{T}$ in the customary scalar lead tracings. It follows, therefore, that the mean spatial $\mathrm{T}$ magnitude, while having a vectorial significance similar to that of the mean spatial QRS magnitude, 
is also analogous to the "total QRS" magnitude since, obviously, algebraic and arithmetic summation of the "areas" under a monophasic deflection give the same value. In some of the athletes, however, the $\mathrm{T}$ complex in at least one of the orthogonal leads (most commonly, lead B) was somewhat diphasic as described earlier, with a terminal component below the iso-electric line. In these cases the $T$ vector magnitude obtained by algebraic summation was used to determine the planar projection angles for $\mathrm{T}$ and the arithmetic summation for estimating the spatial magnitudes.

In contrast with the decrease in mean "total QRS" magnitude in the athletes as compared with the students, the mean spatial $\mathrm{T}$ magnitude did not differ in the short-distance group but was markedly increased in the long-distance competitors. This was due primarily to the increased duration of repolarization (see Table I) rather than to increased maximal voltage attained. Since the increased $\mathrm{T}$ complex time was positively related to total cardiac cycle duration, it would appear that the increased $\mathrm{T}$ magnitude was a consequence of the slower heart rate of the average longdistance runner. In the short-distance group, whose heart rates did not differ significantly from the students', the spatial $T$ magnitudes were unchanged.

A logical development in the analysis of these electrical data would be to consider the ratio of spatial $\mathrm{T}$ vector magnitude to the mean "total $\mathrm{QRS}$ " for each subject. In the untrained subjects this ratio had a mean value of 1.6 (S.D. 0.6), which may well be an index of the relative loss of surface electrical activity during depolarization as a result of the hæmodynamic factors discussed above. This ratio will be modified by any relative changes in either "total QRS" or T such as have been suggested earlier in comparing the manifest electrical activities for the untrained and trained groups. Since total QRS is reduced in the trained subjects and $\mathrm{T}$ is increased, the mean ratio for all athletes is, for both these reasons, increased by approximately 30 per cent to $2 \cdot 1$, with the long-distance group affected to the greater extent. It is possible that, in the absence of organic heart disease or gross electrocardiographic abnormality, the ratio of spatial T magnitude to spatial "total QRS" magnitude could be used as a criterion in the objective assessment of the effect of athletic training on the cardiovascular system.

The concept of the ventricular gradient (VG) first introduced by Wilson et al. (1934) has been regarded by some as of primary importance. Ashman and Byer (1943), for example, have stated that "it is the fundamental quantity of electrocardiography. A change in the gradient reveals a change in the state of the muscle." Others, however, have considered it as having no secure theoretical foundation and as being of only empirical usefulness (Simonson et al., 1954).

In general the gradient may be interpreted as giving a measure of the net difference in electrical events associated with depolarization and repolarization. This difference is to be attributed to two causes, an intrinsic one involving dissimilar time-course relations in the myocardium during the two phases of electrical activity, and an extrinsic cause concerned with the changes in myocardial environment during mechanical diastole and systole.

Almost all previous studies on the ventricular gradient have been confined to investigation of the RLF plane and wide limits of normality have been presented. For example, Goldberger (1953) stated that the direction of the gradient vector may vary from $-20^{\circ}$ to $+90^{\circ}$ with a variation in manifest magnitude from 1.8 to 25 units. Sodi-Pallares and Calder (1956) quote a range of $-17^{\circ}$. to $+86^{\circ}$.

The lead field frontal plane mean ventricular gradient vector angle for the students of the present series was $58^{\circ}$ (S.D. 11), so that 95 per cent of these subjects would be expected to have values lying within the relatively narrow range of $+36^{\circ}$ to $+80^{\circ}$. The greater scatter given by the conventional limb lead data may be regarded as a consequence of using the Einthoven triangular reference frame which has been shown to be inapplicable to the majority of normal subjects (Jordan and Beswick, 1960, $a$ and $b$ ).

The magnitude of the ventricular gradient vector projection on to the RLF and frontal planes bears little direct relation to its true spatial magnitude, since the plane of the QRS and T mean spatial vectors, and therefore of VG, lies approximately normal to the true frontal plane of the body. The spatial ventricular gradient is defined by the diagonal of the parallelogram of forces representing 
the mean vectors for $\mathrm{QRS}$ and $\mathrm{T}$ in space. It follows that, not only will its magnitude be dependent on the magnitudes of $\mathrm{QRS}$ and $\mathrm{T}$, but also on their directions. Its orientation will also be governed by the inter-relation of magnitudes and directions of QRS and T. It is, therefore, possible for the spatial ventricular gradient to remain constant in either direction or magnitude in spite of changes in QRS and T.

In the present study a remarkable feature of the results was the constancy in spatial orientation of the VG vector although its magnitude was significantly greater among the long-distance athletes.

Pathological cardiac hypertrophy with its intrinsic relative ischæmia is usually accompanied by changes in both direction and magnitude of the spatial ventricular gradient, but in the longdistance athlete the hypertrophy must be regarded as the physiological response to physical effort and as associated with increased myocardial capillarization (Jokl, 1958) so that it is reasonable to suppose that the increased magnitude of the gradient vector will not be accompanied by any change in its orientation.

\section{Subsidiary Group of Five Subjects}

Among the untrained student population (Jordan and Beswick, 1958) 8 out of 47 showed vectorial and loop peculiarities that distinguished them individually from the remaining 39 who formed a homogeneous group, and they were, therefore, considered separately. Even in the highly-selected athlete population such unusual forms were also evident, although their incidence had fallen by approximately one-half, i.e. 5 out of 60 . Of these 5 , one was known to have a history of persistent hypertension so that the actual incidence of unusual electrocardiographic patterns in the absence of clinical evidence of cardiac abnormality was only 7 per cent. The planar loops of these 5 subjects are illustrated in Fig. 5 and the corresponding vectorial data are given in Table VI where the symbols employed are those of Jordan and Beswick (1958).

Subject 1, aged 30 years, had a long history of essential hypertension but had continued in competitive athletics on medical advice. His vectorial data and planar loops, with their lack of

TABLE VI

Lead Field Vector Angles and Magnitudes for the Subsidiary Group of Five Athletes

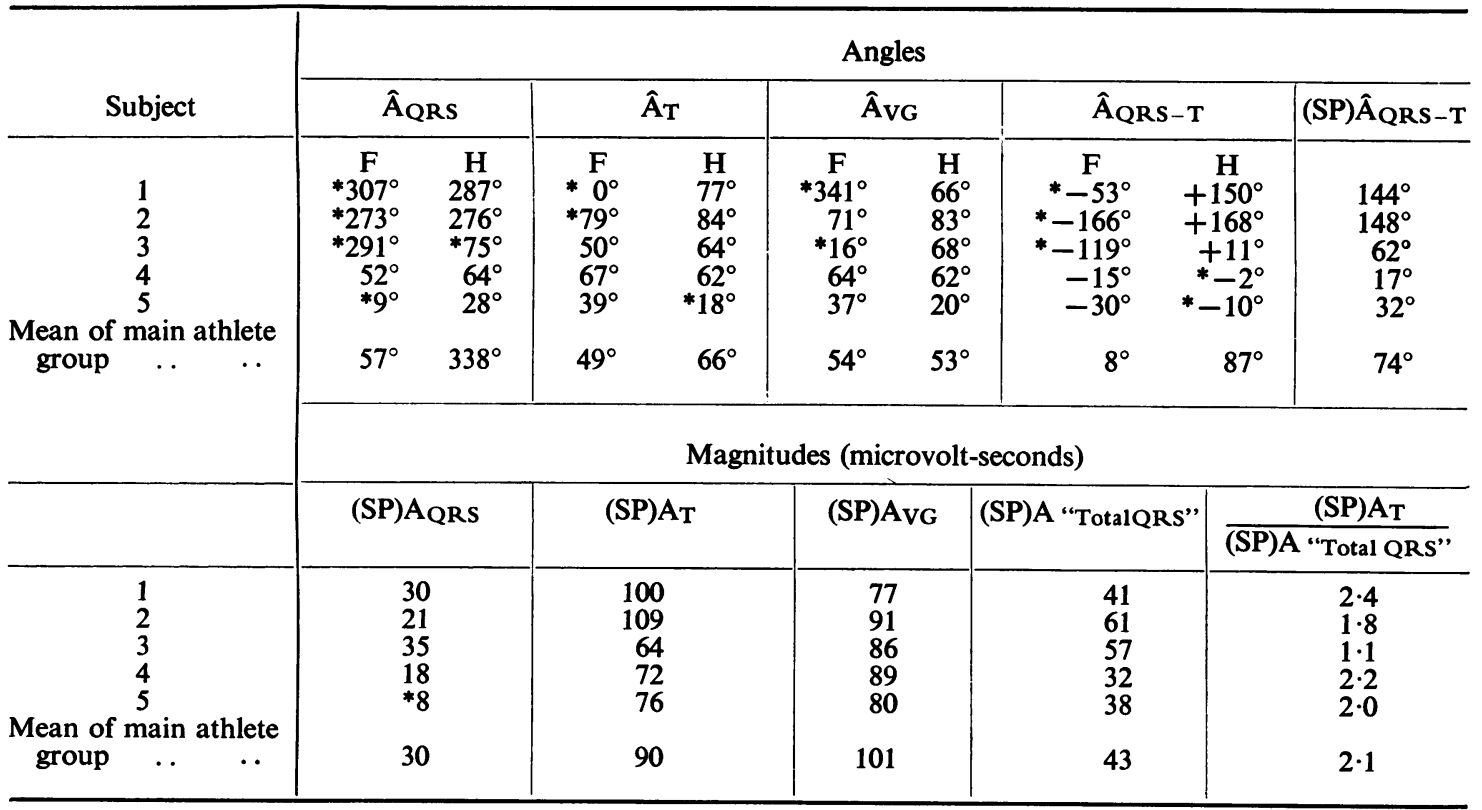

*Values that differ significantly from mean of the main athlete group. 
initial anterior activity and the characteristic contour and horizontal position of the $T$ loop, are typical of left ventricular hypertrophy.

Subject 2 was a 25 -mile road cyclist whose lead field frontal plane QRS vector might have been interpreted as indicating a considerable left axis deviation and whose frontal and sagittal plane loops showed late sustained left ventricular electrical forces. All his horizontal plane vectors were normal and the spatial orientation of $T$ and VG within the usual limits, so that it would appear probable that he was one of the small proportion of normal subjects who have unusually elevated QRS vectors without physical signs of left ventricular hypertrophy.

Subject 3 (a sprinter from British Guiana) had a frontal plane QRS loop and mean vector that might, on casual inspection, appear to indicate extreme left axis deviation similar to that in Subjects 1 and 2. However, the horizontal plane loop and vector angle show that the superior QRS activity is predominantly anteriorly directed and the loop is inscribed clockwise. Subject 3 differs fundamentally from the other two in the horizontal (and sagittal) plane showing changes more suggestive of an extreme degree of the trend towards right ventricular preponderance referred to earlier and illustrated in Fig. 4.

In the case of Subject 4 the loop is characterized by loss of leftward infero-posterior activity so that the projections become very narrow in all three planes and this again is in keeping with a possible relative right-sidedness.

The situation as far as QRS is concerned is similar in Subject 5 but the T loop and planar vector angle in the horizontal plane are posteriorly oriented so that in this plane the QRS-T angle has a negative value. The contour of this $\mathrm{T}$ loop may be regarded as an extreme example of the crescentic deformity described earlier as occurring in about one-third of the athletes.

The broad cardiological implications of this study would suggest that for the individual the spatial electrocardiogram is not necessarily a reliable guide to his fitness to participate in athletics, nor to his state of physical training or probable level of performance. It is well-known that bizarre electrocardiograms are occasionally encountered in the absence of demonstrable heart disease (see, for example, Littmann, 1948; and Kossmann, 1958) and that rarely an outstanding athletic performance may be achieved by someone who has gross cardiac abnormality (Jokl, 1958; Jokl et al., 1958).

However, considered as a group, highly trained athletes do present certain important characteristic features that distinguish them from the untrained and throw some light on their cardiovascular adaptation to repeated severe exercise.

\section{SUMMARY}

The RLF plane electrocardiographic and lead field spatial vectorcardiographic findings for 60 male international-class athletes have been compared with those from 47 untrained students.

The mean heart rate for the athletes as a whole (62) was lower than that for the students by 8 beats a minute, with the long-distance competitors showing the greatest difference (mean: 60). The only statistical difference in time intervals was that the mean $T$ complex time was increased by $0.03 \mathrm{sec}$. in the athletes, while the ratio $Q-T / R-R$ showed a tendency to diminish.

The planar QRS loops of the trained subjects showed generally increased net anterior electrical activity, and in about one-third of cases the T loop was of a peculiar crescentic shape.

Quantitative vectorial and planar loop analyses indicated that 5 of the 60 athletes differed significantly from the remainder and they were considered separately. This proportion was smaller than the corresponding incidence of aberrant individuals in the student group.

Vector angle analysis of the RLF and lead field frontal planes demonstrated that there is no differences between the mean values for students and athletes and that the RLF and true frontal planes bear the same geometrical relations in the two groups.

The major lead field vector angle difference was that the mean spatial QRS-T angle in the athletes was decreased by $26^{\circ}$ due, predominantly, to a less posterior orientation of the QRS vector, 
with $\mathrm{T}$ relatively unchanged. The spatial magnitude of $\mathrm{T}$ was, however, considerably greater in the athletes in consequence of the longer duration of the $T$ complex.

These findings have been discussed as evidence of increased vagal activity and physiological right ventricular hypertrophy in the trained subject in relation to the physical endurance entailed in his competitive event.

Our thanks are due to Air Vice-Marshal M. E. M. Perkins, C.B.E., Station Commander, and Group Captain C. G. Burgess, Officer Commanding Station Hospital, R.A.F., St. Athan, for accommodation and facilities for this work; to Dr. Graham Grant, Secretary of the Medical Committee of the Empire Games and Mr. B. W. Mulrenan for administrative assistance; and to the Medical Research Council for a grant towards the cost of the equipment. We are also indebted to Professor J. M. Peterson and Dr. William Phillips for their encouragement and to Mr. W. Barry, Mr. R. Boothby, and Miss S. Braithwaite for technical and secretarial assistance.

\section{REFERENCES}

Ashman, R., and Byer, E. (1943). Amer. Heart J., 25, 16.

- , and Hull, E. (1941). Essentials of Electrocardiography. Macmillan, New York.

Bazett, H. C. (1920). Heart, 7, 353.

Beckner, G. L., and Winsor, T. (1954). Circulation, 9, 835.

Bramwell, C., and Ellis, R. (1930). Arbeitsphysiologie, 2, 51.

Brouha, L., and Heath, C. W. (1943). New Engl. J. Med., 228, 473.

Chernoff, H. M., and Nahum, L. H. (1949). Fed. Proc., 8, 24.

Cotton, F. S. (1932). J. Physiol., 76, 39.

Cureton, T. K. (1951). Illinois med. J., 99, 143.

Elek, S. R., Allenstein, B. J., Griffith, G. C., Cosby, R. S., and Levinson, D. C. (1954). Amer. Heart J., $47,369$.

Evans, W. (1954). Cardiography. Butterworth, London.

Freedman, M. E., Snider, G. L., Brostoff, P., Kimelblot, S., and Katz, L. N. (1955). J. appl. Physiol., 8, 37.

Fridericia, L. C. (1920). Acta med. Scand., 53, 469.

Glasser, A. (1947). Cardiologia (Basel), 12, 323.

Goldberger, E. (1953). Unipolar Lead Electrocardiography and Vectorcardiography. H. Kimpton, London.

Graybiel, A., McFarland, R. A., Gates, D., and Webster, F. A. (1944). Amer. Heart J., $27,524$.

Gregg, D. E., and Green, H. D. (1940). Amer. J. Physiol., 130, 114.

Grusin, H. (1954). Circulation, 9, 860.

Helm, R. A. (1956). Circulation, 13, 581.

Hoogerwerf, S. (1930). Arbeitsphysiologie, 2, 61.

Hörnicke, E. (1924). Munch, med. Wschr., 71, 1569.

Jokl, E. (1958). The Clinical Physiology of Physical Fitness and Rehabilitation. C. C. Thomas, Springfield.

, Arbeit, S. R., McCubbin, W., Grenier, G., Koskela, A., and Jokl, P. (1958). Amer. J. Cardiol., 1, 199.

Jordan, R. C., and Beswick, F. W. (1958). Circulation, 18, 256.

$\longrightarrow$, (1960 a). Amer. Heart J., 59, 892.

- - (1960 b). Amer. Heart J., 60, 80.

Karpovich, P. V. (1955). Physiology of Muscular Activity. Saunders, Philadelphia.

Karvonen, M. J., Kentala, E., and Mustala, O. (1957). Ann. Med. exp. Biol. Fenn., 35, 307.

Klemola, E. (1951). Ann. Med. intern. Fenn., 40, 121.

Knehr, C. A., Dill, D. B., and Neufeld, W. (1942). Amer. J. Physiol., 136, 148.

Kohlrausch, W. (1921). Munch. med. Wschr., 68, 1515.

Kossmann, C. E. (1958). Trans. Ass. Life Insur. med. Dir. Amer., 41, 101.

Lepeschkin, E. (1951). Modern Electrocardiography. Williams and Wilkins, Baltimore.

Littmann, D. (1946). Amer. Heart J., 32, 370. (1948). Amer. J. Med., 5, 337.

Macleod, A. G. (1938). Amer. Heart J., 15, 165.

McFee, R., and Johnston, F. D. (1953). Circulation, 8, 554.

$\longrightarrow$ - (1954 a). Circulation, 9, 255.

, $(1954$ b). Circulation, 9, 868.

Milnor, W. R. (1957). Circulation, 16, 95.

New York Heart Association (1953). Nomenclature and Criteria for Diagnosis of Diseases of the Heart and Blood Vessels.

Pipberger, H. V., and Tanenbaum, H. L. (1958). Circulation, 18, 1175.

Powell, S. J. (1959). Brit. Heart J., 21, 263.

Reindell, H. (1943). Arch. Kreisl-Forsch., 12, 265.

Richman, J. L., and Wolff, L. (1955). Amer. Heart J., 50, 85.

Robb, J. S. (1950). J. Insur. Med., 6, 29.

, and Turman, W. V. (1947). Amer. J. med. Sci., 214, 180.

Rushmer, R. F. (1959). Amer. J. Physiol., 196, 252.

Savilahti, M. (1946). Acta med. Scand., 123, 252.

Schlamowitz, I. (1946). Amer. Heart J., 31, 329.

Schneider, E. C., and Truesdell, D. (1922). Amer. J. Physiol., 51, 429.

$\mathbf{K}$ 
Segers, M., Regnier, M., Hendrickx, J., and Boyadjian, N. (1956). Brux. med., 36, 1197.

Simonson, E., Schmitt, O. H., Dahl, J., Fry, D., and Bakken, E. E. (1954). Amer. Heart J., 47, 122.

Slapak, L. (1957). Klin. Med. (Wien), 12, 426.

Sodi-Pallares, D., and Calder, R. M. (1956). New Bases of Electrocardiography. H. Kimpton, London.

Steinhaus, A. H. (1933). Physiol. Rev., 13, 103.

Stewart, H. J., and Watson, R. F. (1940). J. clin. Invest., 19, 35.

Terranova, S., and Fernandez, C. (1958). Folia med. (Napoli), 41, 911.

Trethewie, E. R. (1958). Cardiologia (Basel), 32, 345.

White, P. D. (1942). J. Amer. med. Ass., 120, 642.

, and Mudd, S. G. (1929). J. clin. Invest., 7, 387.

Wilson, F. N., Macleod, A. G., Barker, P. S., and Johnston, F. D. (1934). Amer. Heart J., $10,46$.

Winsor, T., and Beckner, G. (1955). Calif. Med., 82, 151.

Wolffe, J. B. (1957). J. Lancet, 77, 76.

Ziegler, R. F. (1951). Electrocardiographic Studies in Normal Infants and Children. C. C. Thomas, Springfield. 